\title{
Inhibition of biofilm formation in Mycobacterium smegmatis by Parinari curatellifolia leaf extracts
}

\author{
Benjamin Bhunu, Ruvimbo Mautsa and Stanley Mukanganyama*
}

\begin{abstract}
Background: Tuberculosis (TB) is a serious public health problem worldwide. Mycobacterium tuberculosis (M. tuberculosis) grows as drug tolerant pellicles. Agents that inhibit biofilm formation in M. tuberculosis have the potential to reduce the disease treatment period and improve the quality of tuberculosis chemotherapy. Parinari curatellifolia (P. curatellifolia) leaf extracts are claimed to treat symptoms similar to tuberculosis in ethnomedicinal practices. Mycobacterium smegmatis (M. smegmatis) is a surrogate organism used in antimycobacterial drug discovery assays. In this study, the effect of the leaf extracts of $P$. curatellifolia on M. smegmatis growth and biofilm formation was investigated in order to determine the basis of its use in traditional medicinal use.

Methods: Phytochemicals from P. curatellifolia leaves were prepared using a mixture of 50\% dichloromethane (DCM): $50 \%$ methanol and by serial exhaustive extraction using different solvents of decreasing polarity. The solvents were used in the following order, hexane $>$ dichloromethane $>$ ethyl acetate $>$ acetone $>$ ethanol $>$ methanol $>$ water. The micro-broth dilution method was used as an antimycobacterial susceptibility test to screen for the extract that effectively inhibited M. smegmatis growth and biofilm formation. Biofilm quantification was performed by staining the biofilms with crystal violet and determining the amount of the stain using a spectrophotometer. In addition, the effects of combining the most active extract with kanamycin were also investigated.

Results: The minimum inhibitory concentrations (MIC) of the extracts were found to be $6.2 \mu \mathrm{g} / \mathrm{ml}$ for the acetone extract, $12.5 \mu \mathrm{g} / \mathrm{ml}$ for both the ethanol and the total extract and $50 \mu \mathrm{g} / \mathrm{ml}$ for both the methanol and ethyl acetate extracts. The ethanol extract, dichloromethane extract and water extract were the only extracts that effectively inhibited biofilm formation in M. smegmatis. Combining the ethanol extract with kanamycin enhanced the effect of the ethanol extract in terms of inhibition of biofilm formation.
\end{abstract}

Conclusions: $P$. curatellifolia leaves contain phytochemicals that have the potential to be used both as antimycobacterial and anti-biofilm formation compounds.

Keywords: Parinari curatellifolia, Biofilm formation, Mycobacterium smegmatis, Tuberculosis, Isoniazid, Kanamycin

\section{Background}

Despite current improvements in the diagnosis and treatment of tuberculosis, the disease remains a serious public health problem globally [1]. In the year 2013, there were approximately 9 million new cases of tuberculosis (TB) and 1.5 million deaths caused by the infection [2]. Countries experiencing the highest burden of

\footnotetext{
* Correspondence: smukanganyama@medic.uz.ac.zW; smukanganyama01@gmail.com

Bio-molecular Interactions Analyses Group, Department of Biochemistry, University of Zimbabwe, P.O. Box MP 167, Mt. Pleasant, Harare, Zimbabwe
}

tuberculosis are from the developing world, especially in Africa and Asia [3]. Some of the factors responsible for the increasing incidence of tuberculosis include the emergence of the HIV (human immunodeficiency virus) pandemic, the deterioration of public health systems in the developing world and the evolution of drug resistant strains of tuberculosis $[4,5]$.

The development of drug resistant phenotypes of tuberculosis is one of the major obstacles hampering effective control of the disease [6]. Isolates that are resistant to one or more anti-tuberculosis drugs have been 
identified [5]. In addition, extensively drug-resistant (XDR), and totally drug-resistant (TDR) M. tuberculosis strains have been reported [7]. The existence of drugresistant MTB phenotypes in an infection extends the treatment period to 20 months and requires the use of sometimes toxic, expensive and less efficient second line anti-TB drugs [5]. In most cases, the chances of successfully treating XDR-TB and TDR-TB are often very low [8]. There is, therefore, an urgent need to introduce new sources of drugs for the treatment of tuberculosis in order to overcome the problem of drug resistance and achieve eradication of the disease [7].

Currently, the main hurdle in TB research is poor understanding of the mechanisms by which MTB evades both the host immune response and antibiotic treatment. In addition, there is poor understanding of the mechanisms used by the pathogen to form persistent infections that exhibit increased drug tolerance [9]. During the early stages of tuberculosis infection, the mycobacterium evades the host immune response and antibiotic action by infecting and hiding within infected host cells such as macrophages [10]. Stress factors such as low oxygen and nutrient concentrations may promote some of the mycobacteria to become dormant and grow into structures that closely resemble biofilms [11].

A number of virulence factors have been discovered that assist the survival of $M$. tuberculosis inside the human host [12]. Approximately $99 \%$ of microbes living in the biosphere are capable of forming multi-cellular communities called biofilms. These are structured communities of sessile bacterial cells embedded within a self-produced matrix. Biofilm matrices are made up of proteins, DNA and polysaccharides that together act as physical and physiological barriers to antimicrobial agents produced by the host immune response or by antibiotics [13]. Studies suggest that biofilms are important in establishing chronic, persistent, drug tolerant infections in most pathogenic and opportunistic bacterial infections [14]. Biofilms thus provide powerful physical barriers to penetration of antibiotics and nutrients [15].

The distribution of Parinari curatellifolia, (Chrysobalanaceae family), is wide spread throughout Africa. This tree has been used as a source of ethnomedicinal extracts in Africa [16]. The traditional uses of the plant include treatment of inflammation, cancer, wounds and bacterial infections and dressing of fractures and dislocations [17]. Other conditions that are claimed to be treated by the plant include, fever, typhoid, and malaria. The plant has also been reported to be effective in treating symptoms similar to tuberculosis [18]. The ability of plant and plant extracts to treat diseases is largely attributed to the presence of phytochemicals. Phytochemicals within the plants show different therapeutic effects in the treatment of various chronic diseases [19]. Plant secondary metabolites also have antiviral and antimicrobial activity. In a study by Tochukwu and Usman [20], a crude extract of $P$. curatellifolia contained the following secondary metabolites; saponins, alkaloids, flavonoids, steroids, tannins, and cardiac glycosides. Other studies screening the phytochemical constituents of $P$. curatellifolia showed similar results and also showed the presence of terpenoids [21]. M. smegmatis is a non-pathogenic mycobacterium and has a drug sensitivity profile comparable to M. tuberculosis [22]. This mycobacterial species can be used in preliminary studies to select compounds with potential activity against M. tuberculosis. Screening extracts against $M$. tuberculosis can be an aseptically rigorous procedure owing to its extremely infective nature. Thus, a biological safety level 3 (BSL3) cabinet has to be used when handling M. tuberculosis [23]. M. tuberculosis also grows slowly, with a generation time of $16-24 \mathrm{~h}$ [24]. The slow growing and highly infectious nature of $M$. tuberculosis has slowed down the discovery of new anti-TB agents [25]. In this study, we used the non-infective M. smegmatis because of its fast growing nature and basic similarities with $M$. tuberculosis. Other researchers studying biofilms in mycobacteria have also used $M$. smegmatis as one of their model organisms [26]. The aim of this study, therefore, was to investigate the antimycobacterial activity of the leaf extracts of $P$. curatellifolia against growth and biofilm formation in $M$. smegmatis.

\section{Methods}

\section{Bacterial strains and reagents}

The bacterium used in this study was the M. smegmatis $155 \mathrm{mc}^{2}$ laboratory strain. It was obtained from Professor Daniel Steenkamp, Department of Clinical Laboratory Sciences, University of Cape Town. Dimethyl sulfoxide (DMSO), Middlebrook 7H9 and Casein hydrosylate were obtained from Sigma Aldrich (Steinheim, Germany). All the reagents used in this study were high grade chemicals obtained from various sources.

\section{Plant collection}

P. curatellifolia fresh leaves were collected from Centenary (Latitude $16^{\circ} 48^{\prime} 00^{\prime \prime} \mathrm{S}$, Longitude $31^{\circ} 07^{\prime} 00^{\prime \prime} \mathrm{E}$, elevation above sea level $1156 \mathrm{~m}$ ) in Mashonaland Central Province of Zimbabwe in the summer period of February 2015. The identity of the plant samples was authenticated by Mr. Christopher Chapano, a taxonomist at the National Herbarium located at the Harare Botanical Gardens, Harare, Zimbabwe. Voucher specimens (C6E7) were made and stored in the Biomolecular Interactions Analyses Laboratory at the Department of Biochemistry, University of Zimbabwe, Harare, Zimbabwe and at the National Herbarium. The leaves were washed with distilled water and then dried in an oven at $40 \mathrm{C}$. The leaf 
powder was prepared using a blender (Philips Co., Shanghai, China). The leaf powder was stored in closed containers at room temperature.

\section{Preparation of plant extracts}

Phytochemicals from $50 \mathrm{~g}$ of powdered $P$. curatellifolia leaf material were extracted by maceration using $500 \mathrm{ml}$ of a solution of $50 \%: 50 \%$ dichloromethane (DCM) and methanol respectively for the total extraction. The mixture was filtered using Whatman No.1 paper. The leaf debris was discarded while the filtrate was left in a sterile fume hood to allow the solvent to evaporate and to completely dry the extract. The amount of extract obtained was measured using an analytical balance and recorded as percentage yield.

Serial exhaustive extraction was carried out sequentially using different solvents of decreasing polarity on the same leaf sample. The serial exhaustive extraction was performed in the following sequence: hexane extraction > DCM extraction > acetone extraction > ethyl acetate extraction $>$ ethanol extraction $>$ methanol extraction $>$ water extraction. At each extraction stage, the leaf debris generated after filtration was left to dry in a sterile fume hood before being used in the subsequent extraction stage. The solvent dissolving the extracts was evaporated and the extracts were left to dry in a sterile fume hood. The mass of each extract was then determined.

\section{Growth of $M$. smegmatis}

M. smegmatis was grown in Middlebrook $7 \mathrm{H} 9$ media $(5.2 \mathrm{~g} / \mathrm{L})$ supplemented with $1 \mathrm{~g} / \mathrm{L}$ casein acid hydrolysate. The media components were dissolved in $40 \mathrm{ml}$ of boiled distilled water and sterilised by autoclaving. A single colony of $M$. smegmatis was inoculated into $20 \mathrm{~mL}$ of media in a $50 \mathrm{ml}$ centrifuge tube and incubated with an appropriate negative control. The tubes were incubated overnight at $37 \mathrm{C}$ with constant shaking at $120 \mathrm{rpm}$ in a Lab Companion incubator (Jeio Tech, Korea).

\section{The effect of $P$. curatellifolia leaf extracts on $M$. smegmatis growth}

The effects of isoniazid, kanamycin and the eight $P$. curatellifolia leaf extracts obtained from the serial exhaustive and total extraction were investigated for their growth inhibitory effect using the microbroth dilution method of Vipra et al., [27]. Isoniazid was dissolved in DMSO to give a solution containing a final concentration of $5 \%$ DMSO and $200 \mu \mathrm{g} / \mathrm{ml}$ isoniazid. The dissolved drug was serially diluted in a 2 -fold manner with media containing 5\% DMSO up to a concentration of $0.8 \mu \mathrm{g} / \mathrm{ml}$ isoniazid. The different concentrations of isoniazid at $100 \mu \mathrm{l}$ each were placed into a 96-well micro- titre plate (Greiner-bione, Sigma- Aldrich, St. Louis, MO, USA). Exponentially growing M. smegmatis culture was standardised using 0.5 McFarland's standard solution to give a cell suspension of $2 \times 10^{6} \mathrm{cfu} / \mathrm{ml}$. A volume of $100 \mu \mathrm{l}$ of the standardised cell suspension was then placed into each well of the 96- well microplate. Determination of cell densitypre-incubation was carried out using a Tecan microplate reader (Tecan Genios-Pro, GrÖdig, Austria) at $590 \mathrm{~nm}$. The plate was then incubated for $24 \mathrm{~h}$ at $37 \mathrm{C}$ in a Lab Companion incubator (Jeio Tech, Korea) without shaking. After the incubation period, cell density was again measured at $590 \mathrm{~nm}$. In order to visualise viable cell growth on the plate, $25 \mu \mathrm{l}$ of 3 -(4, 5-dimethylthiazol-2)-2, 5diphenyltetrazolium bromide (MTT) solution $(1 \mathrm{mg} / \mathrm{ml})$ was added to each well of the microtitre plate containing $200 \mu \mathrm{l}$ of solution. This was followed by an incubation period of $45 \mathrm{~min}$ and a reading of the absorbance of the MTT was taken at $590 \mathrm{~nm}$. A graph of optical density at $590 \mathrm{~nm}$ against isoniazid concentration was then plotted to determine the MIC. The same procedure was carried out to determine the MIC of kanamycin and the plant extracts.

\section{Screening for an extract that effectively inhibits biofilm formation in $M$. smegmatis}

Biofilm formation in M. smegmatis was studied using a method developed by Hawser et al., [28] with some modifications. Polyvinyl chloride (PVC) discs of surface area $1 \mathrm{~cm}^{2}$ were cut from PVC pipes and the disks were sterilized by placing them in $70 \%$ alcohol. Three sterilized disks were placed at equidistant positions in each well of a sterile 6-well Nunclon ${ }^{\mathrm{Tm}}$ (Sigma-Aldrich, Steinheim, Germany) plate. A 24-h old M. smegmatis cell culture was centrifuged at $3500 \mathrm{rpm}$ for $3 \mathrm{~min}$ in a Hettich Rotofix 32 centrifuge (Tuttlingen, Germany). The supernatant of the centrifuged cell culture was discarded and $10 \mathrm{ml}$ of $0.9 \%$ sodium chloride solution was used to wash the cells. The cell suspension was centrifuged $(3500 \mathrm{rpm})$ for $3 \mathrm{~min}$, the supernatant discarded and $5 \mathrm{ml}$ of sterile media added before standardisation with 0.5 McFarland standard solution to give a cell suspension of $5 \times 10^{8} \mathrm{cfu} / \mathrm{ml}$. A volume of $5 \mathrm{ml}$ of the cells were dispensed into each well of the 6 -well plates containing the discs. The plates were incubated at $37 \mathrm{C}$ for $2 \mathrm{~h}$ to allow the cells to adhere to the discs. The non-adherent cells were removed by gentle washing with $5 \mathrm{ml}$ of $0.15 \mathrm{M}$ phosphate buffered saline (PBS) $\mathrm{pH}$ 7.2. The discs were removed from the 6-well plate and each disc was placed singly into each well of a 12-well tissue culture plate containing $3 \mathrm{ml}$ of $100 \mu \mathrm{g} / \mathrm{ml} \mathrm{P}$. curatellifolia leaf extract sample. The extracts, the positive control (kanamycin) and the negative control (DMSO) samples were placed 
in duplicate wells. Another single well containing the PVC disks and no cells served as the sterility control. The plates were incubated for $72 \mathrm{~h}$ at $37 \mathrm{C}$ with shaking $(30 \mathrm{rpm})$. After incubation, the media was removed using a Pasteur pipette and the wells were washed five times with PBS. The biofilms formed were stained by exposing the PVC disks to $4 \mathrm{ml}$ of $0.1 \%$ crystal violet solution and incubating at room temperature for $45 \mathrm{~min}$. The crystal violet was removed by washing three times with distilled water and the plates were left to dry completely. The crystal violet, bound to the biofilms on the discs, was dissolved in $4 \mathrm{mls}$ of $95 \%$ ethanol and its absorbance was measured at $590 \mathrm{~nm}$ using a Tecan microplate reader (Tecan Genios-Pro, Grödig, Austria). The absorbance values were used to plot a graph of biofilm formation versus plant extract concentration. Since the ethanol extract was found to be the most effective at inhibition of biofilm formation, an assay to determine the most effective concentration to inhibit biofilm formation using concentrations of $0-1000 \mu \mathrm{g} / \mathrm{ml}$ was also performed.

\section{The effect of combining the ethanol extract with kanamycin on biofilm formation}

Biofilm formation was carried out as before but with some modifications. The effect of varying kanamycin concentration from its MIC value of $1.6 \mu \mathrm{g} / \mathrm{ml}$ to a quarter of the MIC value whilst keeping the ethanol plant extract concentration constant at $100 \mu \mathrm{g} / \mathrm{ml}$ was investigated. In addition, the effect of varying the ethanol plant extract concentration from $100 \mu \mathrm{g} / \mathrm{ml}$ to $12.5 \mu \mathrm{g} / \mathrm{ml}$ whilst keeping the kanamycin concentration at $1.6 \mu \mathrm{g} / \mathrm{ml}$ was determined.

\section{Statistical analyses}

Statistically significant differences between the mean of the controls and the tests were analysed using one way ANOVA with Dunnett's multiple comparison post-test. The analyses were carried using the software GraphPad Prism 6 (Version 6.03 GraphPad Software Inc. San Diego, California U.S.A).

\section{Results}

Extraction of phytochemicals from $P$. curatellifolia leaves In general, the serial exhaustive extraction method produced a higher amount of plant extract of $9.1 \mathrm{mg}$ combined mass when compared to the total extraction method that produced $6.13 \mathrm{mg}$. In the serial exhaustive extraction, the following masses were obtained for the different solvent extracts; hexane - $0.5 \mathrm{mg}$, DCM $0.42 \mathrm{mg}$, acetone - $2.53 \mathrm{mg}$, ethyl acetate - $0.19 \mathrm{mg}$, ethanol - $0.77 \mathrm{mg}$, methanol - $3.23 \mathrm{mg}$ and water $1.45 \mathrm{mg}$. The total percentage yield of plant extract obtained from the serial exhaustive extraction was $18.19 \%$ compared to $12.25 \%$ using the total extraction method.

\section{The effect of $P$. curatellifolia leaf extracts on $M$. smegmatis growth}

Kanamycin had a minimum inhibitory concentration (MIC) value of $1.6 \mu \mathrm{g} / \mathrm{ml}$ when tested against $M$. smegmatis. Kanamycin was used as the positive control drug as the strain of M. smegmatis used in this study did not respond to $100 \mu \mathrm{g} / \mathrm{ml}$ of isoniazid (Fig. 1). Of all the eight extracts that were investigated for their effects on growth, the acetone extract was the most effective in the inhibition of growth of $M$. smegmatis and produced a MIC of $6.2 \mu \mathrm{g} / \mathrm{ml}$. Both the ethanol extract and the total extractproduced a MIC of $12.5 \mu \mathrm{g} / \mathrm{ml}$. Similar growth inhibitory activities were observed for the methanol extract and ethyl acetate extract (MICs of $50 \mu \mathrm{g} / \mathrm{ml}$ ). The water extract, hexane extract and DCM extract exhibited no activity against M. smegmatis (Figs. 2, 3 and 4).

Screening for an effective $P$. curatellifolia leaf extract that inhibited $M$. smegmatis biofilm formation

Kanamycin, water, DCM and ethanol leaf extracts inhibited biofilm formation in M. smegmatis at the tested concentration of $100 \mu \mathrm{g} / \mathrm{ml}$ (Fig. 5). The ethyl acetate extract and hexane extract had significant anti-biofilm activities however both extracts failed to completely inhibit M. smegmatis biofilm formation. Compared to the control, the acetone extract and the total extract promoted, rather than, inhibited biofilm formation in $M$. smegmatis. The ethanol extract was found to be the most significant at inhibiting biofilm formation at $100 \mu \mathrm{g} / \mathrm{ml}$ concentration. Therefore, lower concentrations of ethanol extract, using a 2 fold serial dilution from 100 to $0 \mu \mathrm{g} / \mathrm{ml}$, were also tested,. However, these lesser concentrations did not significantly inhibit biofilm formation (Fig. 6).

\section{The effects of combining the ethanol extract with kanamycin on $M$. smegmatis biofilm formation}

The effect of kanamycin, at its MIC of $1.6 \mu \mathrm{g} / \mathrm{ml}$, on $M$. smegmatis biofilm formation, was investigated and the drug did not inhibit biofilm formation. M. smegmatis biofilm formation at constant ethanol extract concentration $(100 \mu \mathrm{g} / \mathrm{ml})$ and varying kanamycin concentration, from the MIC value $(1.6 \mu \mathrm{g} / \mathrm{ml})$ to $0.25 \times \mathrm{MIC}$ value, was also investigated. The combination of kanamycin at $1 \times$ MIC, $0.5 \times$ MIC and $0.25 \times$ MIC concentrations with the plant extract at a constant concentration of $100 \mu \mathrm{g} /$ $\mathrm{ml}$ enhanced biofilm formation. The effectiveness of the ethanol extract at inhibiting biofilm formation was also enhanced by combining the different ethanol extracts concentration with a constant concentration of 


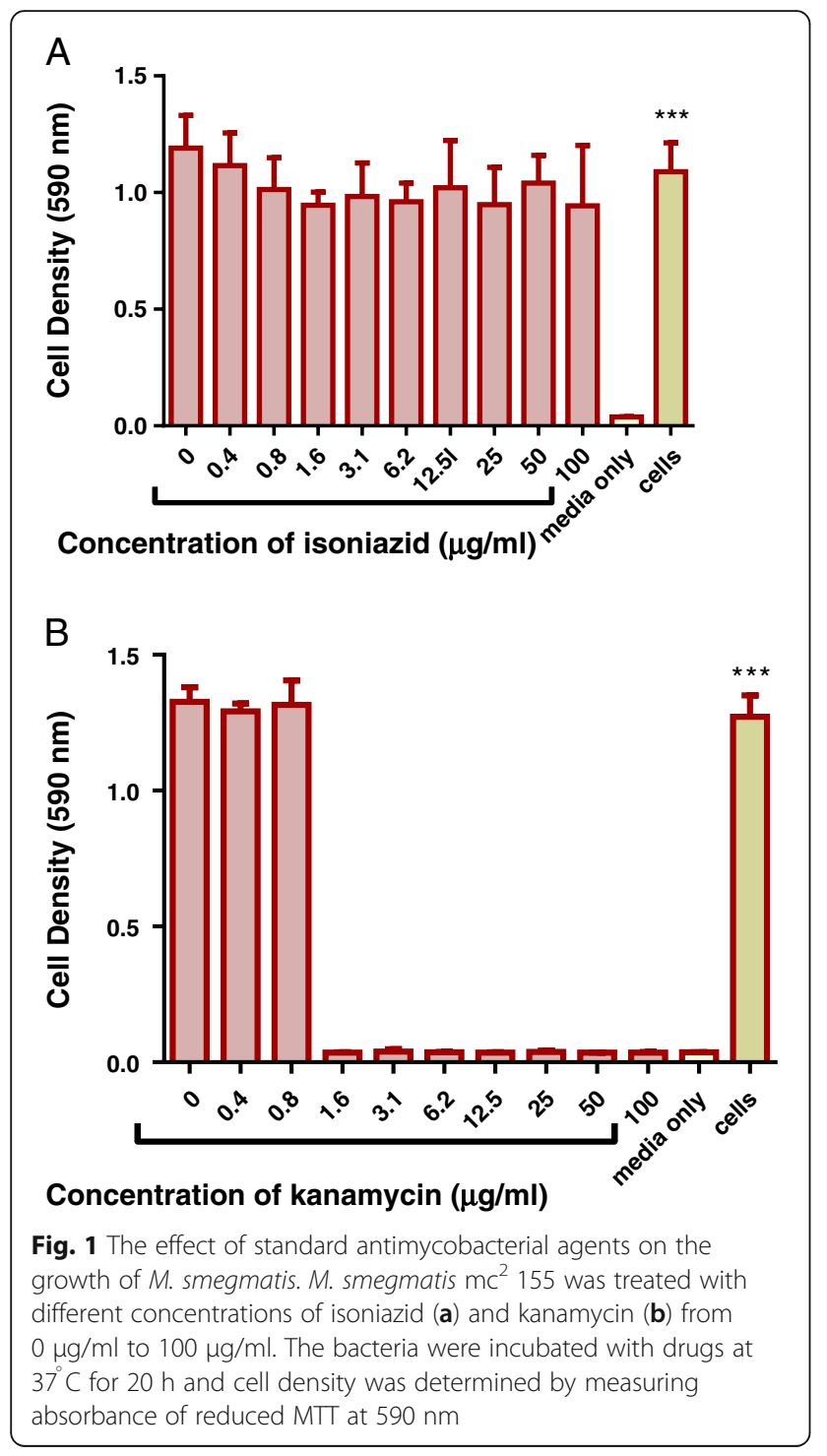

kanamycin at $1.6 \mu \mathrm{g} / \mathrm{ml}$. However, at a concentration of $12.5 \mu \mathrm{g} / \mathrm{ml}$, the ethanol extract combined with kanamycin promoted biofilm formation (Fig. 7).

\section{Discussion}

The objective of this study was to investigate the effects of $P$. curatellifolia leaf extracts on $M$. smegmatis biofilm formation. The effect of the extract on biofilm formation was determined after initially assessing whether the extracts inhibited the growth of the cells. M. smegmatis is a surrogate mycobacterium used in preliminary antitubercular drug discovery assays [29]. The key aspects of M. tuberculosis biology are reminiscent of biofilm behaviour, for example, the ability of tuberculosis to grow in cell culture as bacterial clumps called cords, which are a correlate of virulence [30]. M. tuberculosis is able to effectively survive inside the human host and produce persistent infections despite rigorous drug treatments

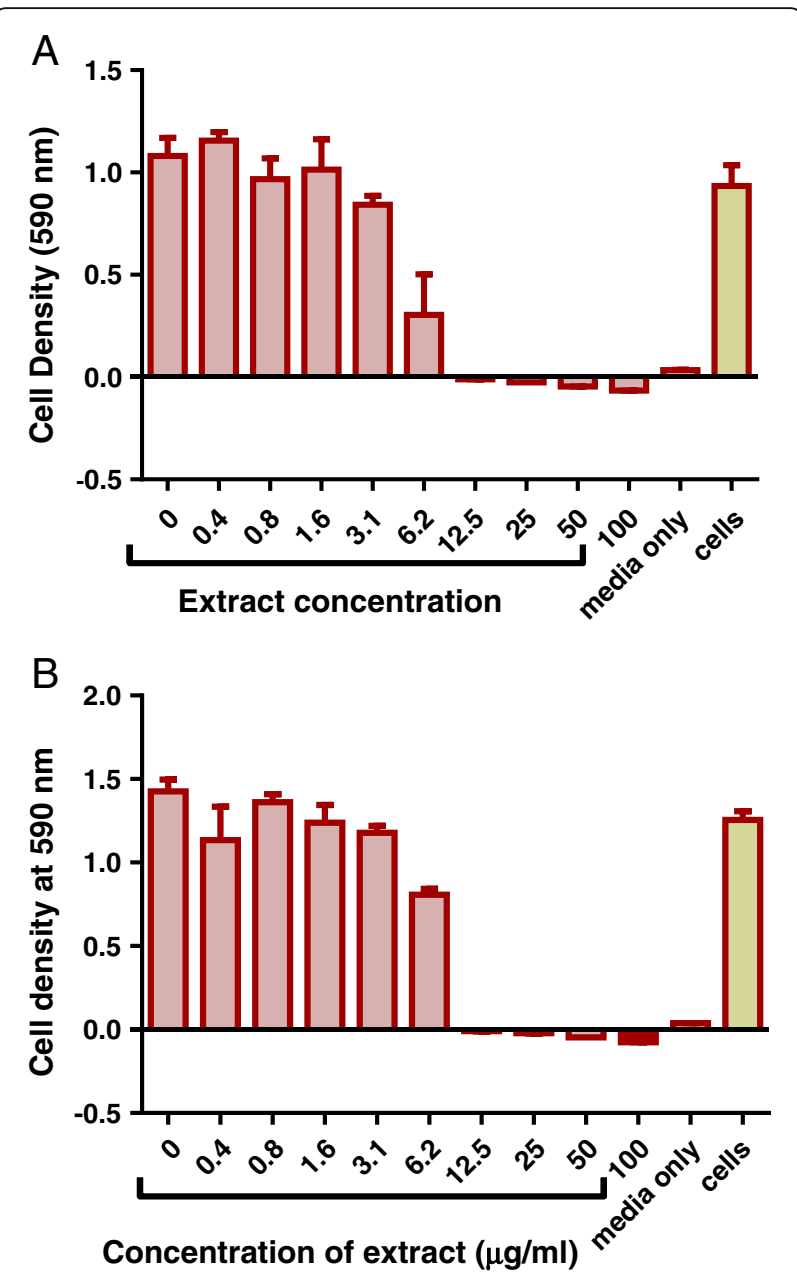

Fig. 2 The effect of $P$. curatellifolia acetone and ethanol extracts on the growth of $M$. smegmatis. M. smegmatis mc $^{2} 155$ laboratory strain at concentration of $2 \times 10^{6} \mathrm{cfu} / \mathrm{mL}$ was treated with different concentrations of the acetone (a) and ethanol extract (b) from $0 \mu \mathrm{g} / \mathrm{ml}$ up to $100 \mu \mathrm{g} / \mathrm{ml}$. The bacteria were incubated with extracts at $37^{\circ} \mathrm{C}$ for $20 \mathrm{~h}$ and cell density was determined by measuring absorbance of reduced MTT at $590 \mathrm{~nm}$. The error bars on the graphs indicate the standard deviation from mean $(n=4)$. Dunnet's multiple comparison test was used to compare columns using Graphpad prism 6 software. The asterisks $\left(^{*}\right)$ indicate statistical significant differences with the sterility control (media) ${ }^{*}<0.05^{* *}<0.0001$

and the presence of an active immune response [31]. In addition, the treatment of tuberculosis takes a long period, ranging between six to nine months and the infection is often characterised by relapsing infections after discontinuing drug therapy [32]. In humans, clumps of $M$. tuberculosis contained in an acellular matrix have been found. The clumps were located in certain caveating lesions that were undergoing liquefaction in the human lungs [33]. All these characteristics of Mtb are reminiscent of an organism that is able to produce biofilms. 


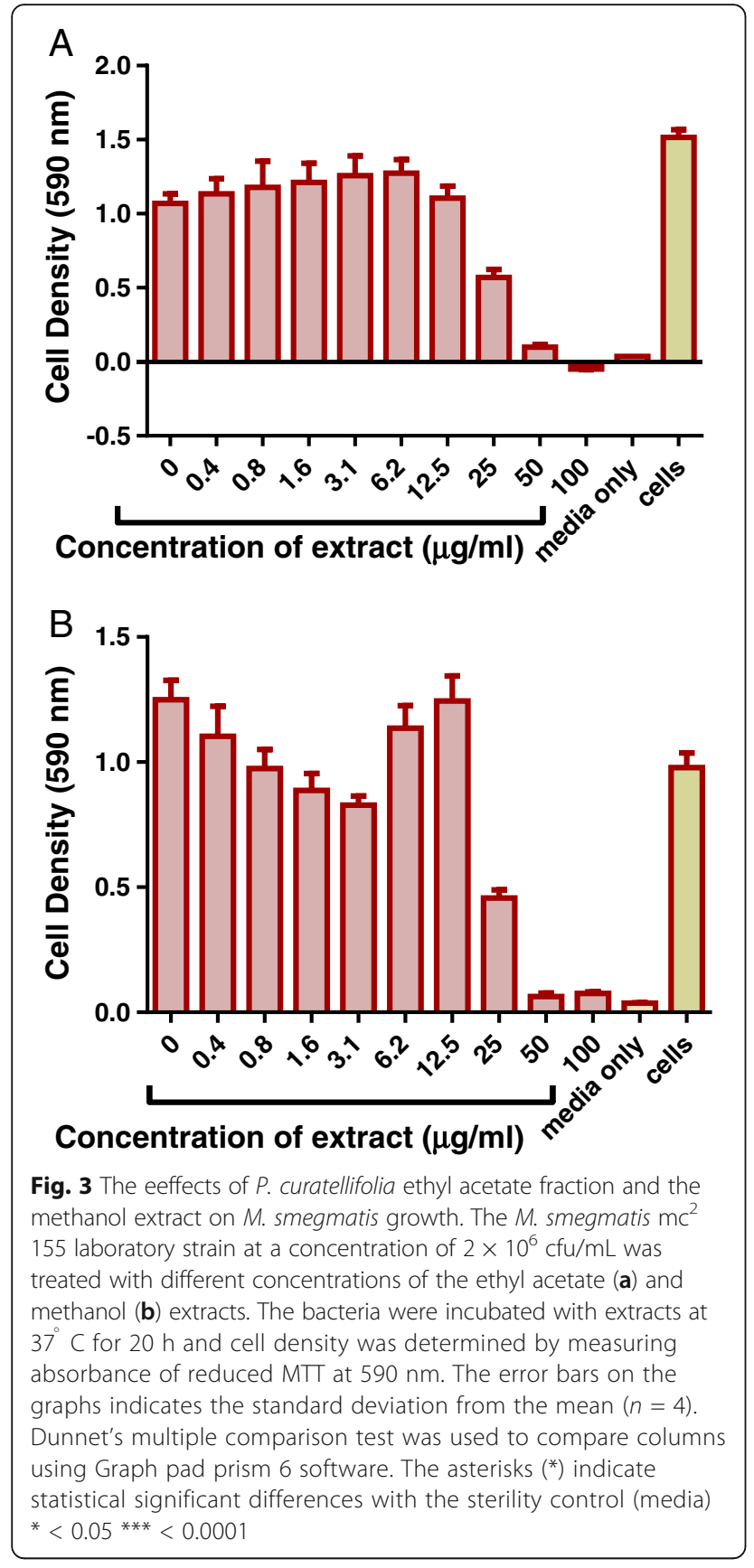

Biofilm formation by various pathogenic organisms has been demonstrated to be tolerant to elevated levels of various antimicrobials [15, 33]. Ojha et al., [14] showed that $M$. tuberculosis grows in structures similar to biofilms called pellicles and these colonies were found to be drug-resistant. In addition, in the same study, tuberculosis pellicles were shown to confer drug resistance to drug susceptible $M$. tuberculosis mutants. Therefore, targeting $M$. tuberculosis biofilms is a potential way of improving TB chemotherapy.

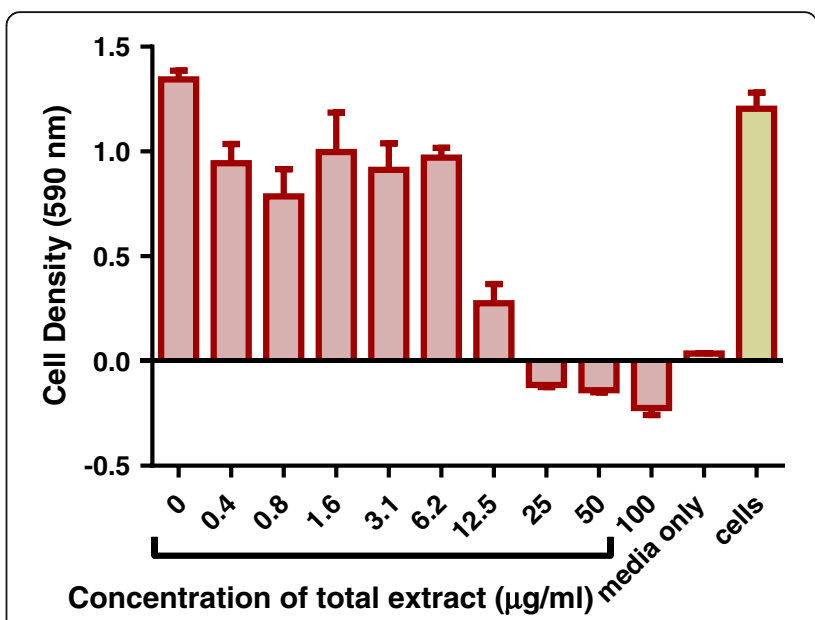

Fig. 4 The effects of $P$. curatellifolia total extract on M. smegmatis growth. The M. smegmatis $\mathrm{mc}^{2} 155$ laboratory strain at a concentration of $2 \times 10^{6} \mathrm{cfu} / \mathrm{mL}$ was treated with the total extract from concentration of $0 \mu \mathrm{g} / \mathrm{ml}$ to $100 \mu \mathrm{g} / \mathrm{ml}$ of the plant extract. The bacteria were incubated with extracts at $37^{\circ} \mathrm{C}$ for $20 \mathrm{~h}$ and cell density was determined by measuring absorbance of reduced MTT at $590 \mathrm{~nm}$. The error bars on the graphs indicate the standard deviation from mean $(n=4)$. Dunnet's multiple comparison test was used to compare the columns using graph pad prism 5 software. The asterisks $\left(^{*}\right)$ indicate statistical significant differences with the sterility control (media) ${ }^{*}<0.05^{* * *} 0.0001$

P. curatellifolia is claimed to treat symptoms similar to tuberculosis $[18,34]$. There have been previous studies conducted to investigate the anti-mycobacterial properties of the plant and these confirmed the antimicrobial activity of the plant extracts against $M$. aurum [35]. P.

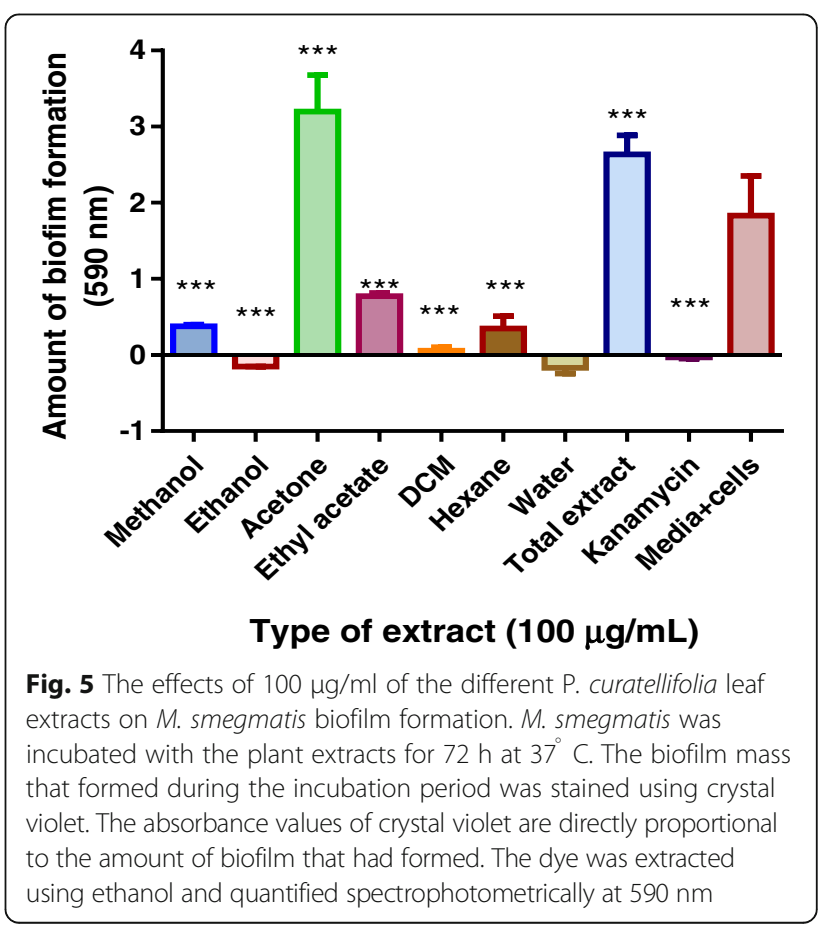




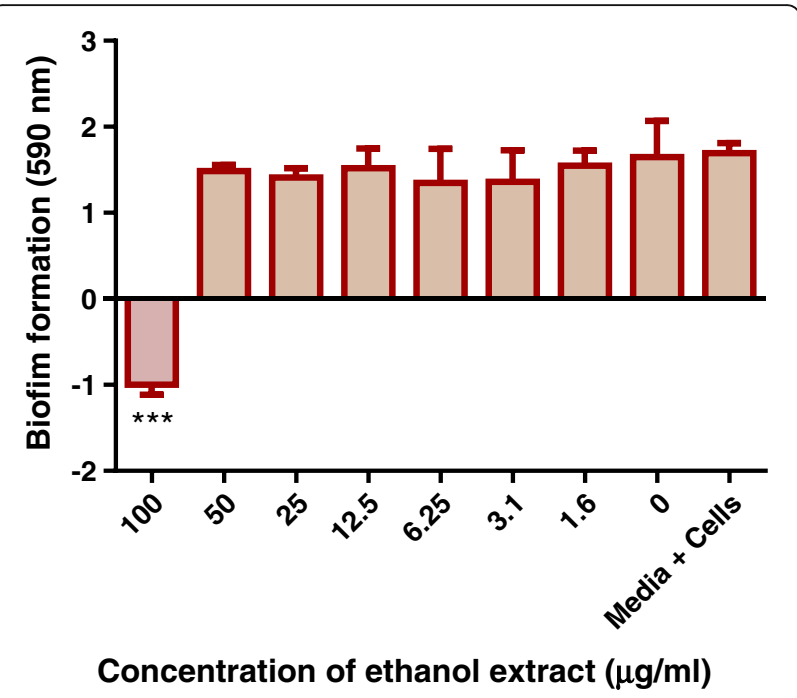

Fig. 6 The effect of the different concentrations of the ethanol extract on M. smegmatis biofilm formation. M. smegmatis was incubated in different concentrations of the ethanol extract of P. curatellifolia leaf powder for $72 \mathrm{~h}$ at $37^{\circ} \mathrm{C}$. The biofilm mass that formed during the incubation period was stained using crystal violet staining which was quantified spectrophotometrically at $590 \mathrm{~nm}$. The error bars indicates the standard deviation from mean $(n=4)$. Dunnet's multiple comparison test was used to compare columns using graph pad prism 5 software. The asterisks $\left(^{*}\right)$ indicate statistical significant differences with the growth control (media + cells) ${ }^{*}<0.05^{* * *}<0.0001$

curatellifolia has also been shown to have antibacterial activity against a variety of bacterial species [36]. Phytochemical analysis of $P$. curatellifolia plant leaves has demonstrated the presence of saponins, steroids, alkaloids tannins, flavonoids and cardiac glycosides [37]. The presence of these secondary metabolites in the plant leaves indicate the potential use of the plant as a source of antimicrobial agents. The percentage yield of P. curatellifolia leaf extract from the total extraction and serial exhaustive extraction was $12.25 \%$ and $18.19 \%$ respectively. The percentage yield results suggest that the serial exhaustive extraction is a better extraction method than the total extraction (50\% DCM: 50\% Methanol) since more mass of the extract was obtained from the serial exhaustive extraction compared to the total extraction. The serial exhaustive extraction method used solvents with varying polarities to extract phytochemicals from the plant. In contrast, in the total extraction method, the solvent used was an immiscible mixture of methanol and DCM. Methanol is highly polar, while DCM is nonpolar [38]. From the serial exhaustive extraction it was noted that more phytochemicals were extracted using polar solvents than non-polar solvents. Methanol was the most effective solvent for extraction followed by acetone and then water. These three solvents are polar in nature; water and methanol extract only polar phytochemicals, while acetone extracts both non polar and polar phytochemicals [39]. The majority of phytochemicals in P. curatellifolia leaves are polar compounds since phytochemicals are extracted more with solvents of a more polar nature.

Kanamycin is a second-line tuberculosis drug [40]. The use of kanamycin as a positive control in this study arose as a result of the insensitivity that was displayed by $M$. smegmatis towards isoniazid. The MIC value for kanamycin was found to be $1.6 \mu \mathrm{g} / \mathrm{ml}$. In a study conducted by Taniguchi et al., [41], aimed at analysing the molecular resistance to kanamycin in M. smegmatis, the MIC value for the wild type M. smegmatis was found to be $5 \mu \mathrm{g} / \mathrm{ml}$. In another study done by Danilchanka et al., [42], designed to investigate the role of porins in the uptake of antibiotics by $M$. smegmatis, the wild type $M$. smegmatis was found to have an MIC value of $1.25 \mu \mathrm{g} /$ $\mathrm{ml}$. The MIC values obtained in this study are thus comparable with values obtained in other reports.

Of the eight extracts studied, the acetone extract was the most effective extract at inhibiting the growth of $M$. smegmatis. When the acetone extract was shaken, it produced froth indicating the presence of saponins [16]. Acetone is known to extract both hydrophilic and hydrophobic phytochemicals [39] and it is likely that the acetone extract contained a higher number of phytochemical species than the other extracts by the virtue of the mass obtained. The other extracts from $P$. curatellifolia leaves such as the ethanol extract, total extract, methanol and ethyl acetate also had significant bioactivities against $M$. smegmatis, although these activities were less than that of the acetone extract. The existence of more than one plant extract which was active against $M$. smegmatis suggests that $P$. curatellifolia leaves are a rich source of bioactive compounds that have the potential to lead to discoveries of new anti-mycobacterial compounds.

The activity produced by the extracts could be due to the presence of individual phytochemicals which are active against $M$. smegmatis or could be as a result of the synergistic effect of two or more phytochemicals that are contained in the extracts [43]. Isolation and purification of each of the individual phytochemicals that are contained in the extracts is required to determine if the bioactivity that was produced by the extracts is a result of a single phytochemical or if it was as a result of the combined effect of several phytochemicals. If the activity exhibited by the extracts was as a result of single compounds, those compounds may be used as candidates for new anti-mycobacterial drug discovery.

The water, DCM and ethanol extracts were found to be effective at inhibiting biofilm formation in $M$. smegmatis. However, the DCM and water extract had no appreciable bioactivities against the growth of $M$. 

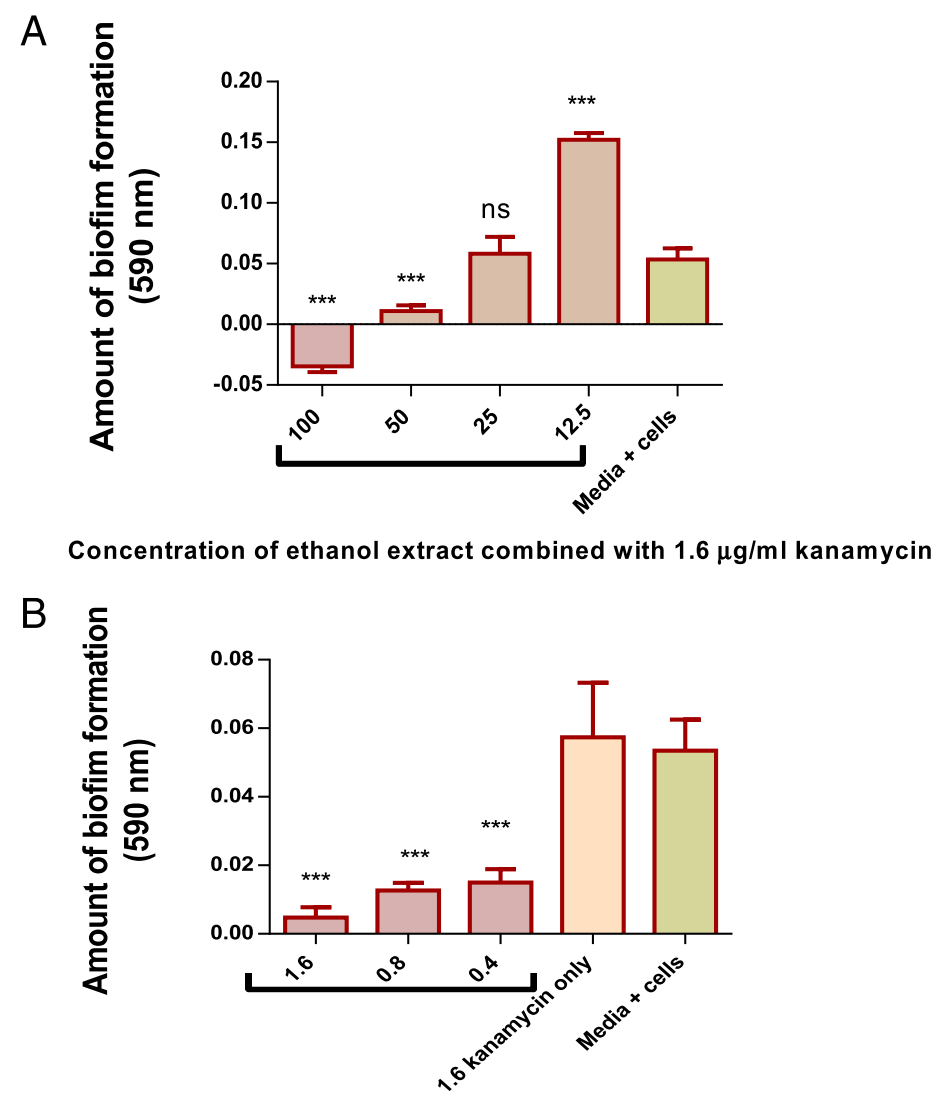

\section{Concentration of kanamycin combined with $100 \mu \mathrm{g} / \mathrm{ml}$ ethanol extract}

Fig. 7 The effect of combining P. curatellifolia ethanol extract with kanamycin. a M. smegmatis was incubated in a medium containing $1.6 \mu \mathrm{g} / \mathrm{ml}$ kanamycin and varying ethanol extract concentration for $72 \mathrm{~h}$. The amount of biofilm that had formed was determined by staining the biofilms with crystal violet, dissolving the crystal violet on the stained biofilms and spectrophotometrically measuring the amount of dye. $\mathbf{b} \mathrm{M}$. smegmatis was incubated for $72 \mathrm{~h}$ in a medium containing $100 \mu \mathrm{g} / \mathrm{ml}$ ethanol extract and varying concentration of kanamycin from MIC value to quarter MIC value. The Error bars indicates the standard deviation from mean $(n=4)$. Dunnet's multiple comparison test was used to compare columns using graph pad prism 5 software. The asterisks $\left(^{*}\right)$ indicate statistical significant differences with the growth control (media + cells) $*<0.05^{* * *}<0.0001$

smegmatis. Traditional healers use water as a solvent to extract phytochemicals from plant materials when treating different kinds of illness Sasidharan et al., [44]. In most phytochemical studies, the water extracts of different plants are reported to have no bioactivities [45]. Results from this study suggest that the water extract does not necessarily kill microbes but, rather, the extract prevents the clumping together of microbes. The clumping of microbes during the course of an infection leads to formation of microbial biofilms. When microbes are prevented from forming biofilms, they are eft exposed to the vast immune intervention mechanisms produced by the host against the pathogens [14].

Despite having an excellent anti-mycobacterial activity, the acetone extract, failed to inhibit M. smegmatis biofilm formation but rather promoted it at the tested concentration of $100 \mu \mathrm{g} / \mathrm{ml}$. The acetone extract might have contained antibacterial phytochemicals that stimulate a stress response in the bacteria. Several studies have demonstrated that when microbes are stressed, such as under antibiotic treatment, genes associated with biofilm formation are stimulated and the bacteria convert to the biofilm phenotype [9]. It is likely that this extract failed to inhibit biofilm formation, but instead induced stress that stimulated the bacteria to switch into the biofilm phenotype from planktonic form. At $50 \mu \mathrm{g} / \mathrm{ml}$ the ethanol extract failed to inhibit $M$. smegmatis biofilm formation but it had a MIC of $12.5 \mu \mathrm{g} / \mathrm{ml}$. These results suggest that the inhibition of $M$. smegmatis biofilm formation requires a higher concentration of the extract sample than the concentration that is required to inhibit bacterial growth. The different durations of incubation with the extract for each assay could also account for the variations in sensitivity to the extracts observed. In the growth inhibitory assays, $M$. smegmatis was incubated for $24 \mathrm{~h}$ in the presence of the extract. In the 
inhibition of the biofilm formation assay, the mycobacteria were incubated with the extract for $72 \mathrm{~h}$.

When kanamycin was used alone at MIC value, the drug failed to inhibit biofilm formation. When kanamycin, at $0.25 \times$ MIC value was combined with the extract, biofilm formation was then inhibited. It was important to determine if kanamycin had any significant effects on biofilm formation in the combined extract/kanamycin mixture since kanamycin at MIC had failed to inhibit $M$. smegmatis biofilm formation. To further explore this finding, the pattern of biofilm inhibition at varying extract concentration and constant kanamycin concentration at the MIC value were determined. It was noted that $50 \mu \mathrm{g} / \mathrm{ml}$ of the ethanol extract inhibited M. smegmatis biofilm formation but had failed to inhibit growth. These results, therefore, suggested a synergistic effect between the extract and kanamycin.

P. curatellifolia ethanol leaf extract has been confirmed to contain phytochemicals such as steroids, tannins, flavonoids and saponins [26] and these phytochemicals have been demonstrated to associate with bacterial proteins and inhibit microbial adhesion, enzymes, cell envelop and transport proteins [46-48]. It is, therefore, likely that the ethanol extract inhibited biofilm formation through some of these mechanisms. Bacterial adhesion is important during biofilm formation [49] and agents that disrupt bacterial adhesion to surfaces have the potential to act as anti-biofilm agents.

It was also found that the ethanol extract at a lower concentration of $12.5 \mu \mathrm{g} / \mathrm{ml}$, when combined with $1.6 \mu \mathrm{g} / \mathrm{ml}$ kanamycin, actually promoted biofilm formation. A possible explanation for this observation is that the extract/kanamycin mixture at that concentration was less effective and did not inhibit biofilm formation. Therefore, $M$. smegmatis were able to form the colonies that transform into biofilms. It is possible that this extract/ kanamycin mixture might have induced antibiotic stress in the bacteria [50], resulting in the development of bacilli that were more adapted to the antibiotic/extract mixture and could grow vigorously into biofilms as observed.

\section{Conclusion}

In conclusion, our study showed that the leaves from $P$. curatellifolia are a potential source of phytochemicals with activity against the growth and biofilm formation of M. smegmatis. The water, DCM and ethanol leaf extracts of $P$. curatellifolia inhibited biofilm formation. Extracts that inhibit M. smegmatis growth do not necessary inhibit biofilm formation. Combining the ethanol extract with kanamycin had an effect of enhancing the antimycobacterial effect of the extract. Further studies with purified compounds from $P$. curatellifolia need to be carried out from the ethanol extract, water and DCM extracts in order to isolate phytochemicals that inhibit biofilm formation in M. smegmatis. In addition further work needs to be carried out to determine if the same effects are observed with the clinical mycobacterial strain M. tuberculosis.

\begin{abstract}
Acknowledgements
The authors acknowledge the assistance of Mr. Christopher Chapano, a taxonomist with the National Herbarium and Botanical Gardens, Harare, Zimbabwe in the authentication of the plant sample names. The authors would also like to acknowledge the assistance in English grammar editing by Dr. Fiona Robertson of the Department of Biochemistry, University of Zimbabwe.

Funding

Support from the International Science Programmes (ISP) through the International Program in the Chemical Sciences (ISP IPICS: ZIM01, Uppsala University, Uppsala, Sweden) and the International Foundation in Sciences (IFS F/3413-03F, Stockholm, Sweden) us acknowledged. F/3413-03F supported research under the title: "Screening natural plant products from selected plants from Zimbabwe as a source of anti-infective compounds for phytomedicines development". ISP IPICS: ZIM01 supported the research under the title "Biomolecular Interactions Analyses".
\end{abstract}

Availability of data and materials

The data sets generated during and/analysed during the current study are available in the University of Zimbabwe Digital Collections Repository: Postgraduate Thesis and Undergraduate Dissertations

http://digitalcollections.uz.ac.zw:8080/xmlui and from the corresponding author on reasonable request.

\section{Authors' contributions}

BB, RM and SS conducted the experimental studies and data analyses. SM conceptualized, designed and directed the study. BB, RM, SS and SM

finalized the manuscript. All authors read and approved the final manuscript.

\section{Authors' information}

Dr. Stanley Mukanganyama is an associate professor of Biochemistry at the University of Zimbabwe. He holds a PhD in Biochemistry and specialised in drug metabolism, particularly the contribution of Phase II enzyme systems in xenobiochemistry. $\mathrm{He}$ is a member of the Biochemistry and Molecular Biology Society of Zimbabwe (BMBSZ), is the Head of the Department of Biochemistry and the In-country president of the Natural Products Research of Eastern and Central Africa (NAPRECA-Zimbabwe. Ms. Ruvimbo Mautsa (BSc. Biochemistry) is Teaching Assistant and postgraduate student in the Department of Biochemistry. Mr. Simbarashe Sithole (BSC. Hons Chemical Technology) is Technician in the Department of Biochemistry.

Competing interests

The authors declare that they have no competing interests.

Consent for publication

Not applicable.

Ethics approval and consent to participate

The study was approved by the Department of Biochemistry Board (BC36/ 2015) Harare, Zimbabwe).

\section{Publisher's Note}

Springer Nature remains neutral with regard to jurisdictional claims in published maps and institutional affiliations.

Received: 15 December 2016 Accepted: 19 May 2017

Published online: 30 May 2017

\section{References}

1. World Health Organisation. Global Tuberculosis Report 2013, World Health organization, Geneva, Switzerland. 2014. pp. 54-60. www.who.int/tb/ publications/global_report/en. Accessed 16 July 2016.

2. World Health Organisation. WHO Global Tuberculosis Report. 2014/ 2013. http://www.who.int/tdr/news/2013/global-TB-report/en/. Accessed 19 July 2016. 
3. Maher D, Raviglione M. Global epidemiology of tuberculosis. Clin Chest Med. 2005:183-95.

4. Lienhardt C, Raviglione M, Hafner R, Jaramillo E, Hoelcher M, Zumla A, et al. New drugs for the treatment of tuberculosis: need, challenges, promise and prospects for future. J Infect Dis. 2012;205:S241-9. doi:10.1093/infdis/jis034.

5. Kwan CK, Ernst JD. HIV and tuberculosis: a deadly human Syndemic. Clin Microbiol Rev. 2011:351-76.

6. Green KD, Carneau-Tsodikova S. Resistance in tuberculosis: what do we know and where can we go? Front Microbiol. 2013;4:208. doi:10.3389/fmicb. 2013.00208. eCollection 2013

7. Veleyati AA, Masjedi RM, Forma P, Tabarsa P, Ghavani J, Ziazariffi A, et al. Emergency of new forms of totally drug resistant tuberculosis bacilli: super extensively drug resistant tuberculosis or totally drug resistant strains in Iran. Chest. 2009;136(2):420-5. doi:10.1378/chest.08-2427.

8. Blanco D, Perez-Herran E, Cacho M, Ballell L, Castro J, González Del Río R, et al. Mycobacterium tuberculosis gyrase inhibitors as a new class of antitubercular drugs. Antimicrob Agents Chemother. 2014:59:1868-75. doi:10.1128/AAC.03913-14.

9. Ackart D, Hascal-Dove L, Ceres SM, Kirk N, Podell B, Maled C, et al, Expression of antimicrobial tolerance by attached communities of Mycobacterium tuberculosis. Pathog Dis. 2013;70:359-69.

10. Lee W, Vanderven BC, Fahey RS, Russel DG. Intracellular Mycobacterium tuberculosis exploits host derived fully acids to limit metabolic stress. J Biol Chem. 2013;288:6788-800.

11. Hett EC, Rubin EJ. Bacterial growth and cell division: a mycobacterial perspective. Microbiol Mol Biol Rev. 2008; 72: 126-156. doi: 10.1128/MMBR. 00028-07 PMCID: PMC2268284.

12. Brosch R, Gondon SV, Brodin PA. A new evolutionary scenario for the Mycobacterium tuberculosis complex. Proc Natl Acad Sci U S A. 2002;99: 3680-9.

13. Anderson GG, Parkermo JJ, Schilling JD, Roth R, Henster J. Intracellular bacterial biofilm-like pods in urinary tract infections. Science. 2003;301:105-7.

14. Ojha A, Anand M, Jacobs WR, Bhatt A, Kreme L, Hatfull GF. GroEli: a dedicated chaperone involved in mycolic acid biosynthesis during mycobacterial growth in biofilms. Cell. 2015;123:861-73.

15. Mu H, Guo F, Niu N, Wang S, Duan V. Chitosan improves anti-biofilm efficacy of gentamicin through facilitating antibiotic penetration. Int J Mol Sci. 2007:15:22296-308. doi:10.3390/ijms151222296.

16. Pandey A, Tripathi S. Concept of standardization, extraction and prephytochemical screening strategies for herbal drug. J Pharmacogn Phytochem. 2004;2:115-9.

17. Srivastav DNS, Suresh T. Antimicrobial activity of certain medical plants using in folkloric medicine. J Ethnopharmacol. 2001;74:217-22.

18. Chigora P, Masocha R, Mutenheri F. The role of indigenous medicinal knowledge (IMK) in the treatment of ailments in rural Zimbabwe: the case of Mutirikwi communal lands. J Sust Dev Afr. 2007;9:1509-20.

19. Mukhopadhyay MK, Banerjee P, Nath D. Phytochemicals - biomolecules for prevention and treatment of human diseases-a review. IJSER. 2012;3(7):1-32.

20. Tochukwu HE, Usman WA. Curative effect of Parinari curatellifolia leaf extract on epiglottitis. J Pharm Biol Sci. 2013;5(6):46-51.

21. Halilu ME, Yebpella GG, Hassan LG, Achor M. Preliminary phytochemical screening, antibacterial activity and elemental analysis of the leaves and the root bark of Parinari curatellifolia planch ex. Benth (Chrysobalanaceae). C J Pharm Sci. 2010;4:1-5.

22. Sousa S, Bandeira M, Carvalho PA, Duarte A, Jordao L. Nontuberculous mycobacteria pathogenesis and biofilm assembly. Int J Mycobacteriol. 2015; 4(1):36-43.

23. Barua CC, Singh A, Sen S, Barua AG, Barua IC. In vitro antioxidant and antimycobacterial activity of seeds of Piper longum Linn: A comparative study. SAJ Pharmacy and Pharmacology, 2014. 1: 101. doi: 10. 18875/23752262.1.101.

24. Current draft WHO-CDC Biosafety recommendations. http://www.stoptb.org/wg/gli/assets/documents/Mtg2pres/01\%20\%20Current\%20draft\%20WHO-CDC\%20Biosafety\%20recommendations.pdf. Accessed 28 June 2016.

25. Kisangau DP, Hosea KM, Joseph CC, Lyaruu HVM. In vitro antimicrobial assay of plants used in traditional medicine in Bukoba rural district, Tanzania. Afr J Tradit Complement Altern Med. 2007:4:510-23.

26. Kaur P, Ghosh A, Krishnamurthy RV, Bhattacharjee DG, Achar V, Datta S, et al. A high-throughput cidality screen for Mycobacterium tuberculosis. PLoS One. 2015;10(2):e0117577. doi:10.1371/journal.pone.0117577.
27. Vipra A, Desai SN, Junjappa RP, Roy P, Poonacha N, Ravinder P, et al. Determining the minimum inhibitory concentration of bacteriophages: potential advantages. Adv Microbiol. 2013;3:181-90.

28. Hawser PS, Douglas JL. Biofilm formation by Candida species on the surface of catheter material in vitro. Infect Immun. 1994;62:915-21.

29. Nguta JM, Regina AO, Nyarko AK, Manu DY, Addo PGA. Current perspectives in drug discovery against tuberculosis from natural products. Int J Mycobacteriol. 2015;4:165-83.

30. Basaraba RJ. Experimental tuberculosis: the role of comparative pathology in the discovery of improved tuberculosis treatment strategies. Tuberculosis (Edinburg). 2008:S135-47.

31. Smith I. Mycobacterium tuberculosis pathogenesis and molecular determinants of virulence. Clin Microbiol Rev. 2003;16:463-96.

32. Casterton JW, Greenberg EP, Sterwart PS. Bacterial biofilms: a common cause of persistent infections. Science. 1991;284:1318-22.

33. Wu H, Moser C, Wang H-Z, Høiby N, Song Z-J. Strategies for combating bacterial biofilm infections. Int J Oral Sci. 2014;7:1-7.

34. Matongo K. Conservation and use-values of medicinal plants in rural Eastern Zimbabwe: a study of selected medicinal plants. University of the Western Cape, Magister Artium Thesis. University of the Western Cape, South Africa. 2012.

35. Chimponda T, Mukanganyama S. Antimycobacterial activities of selected medicinal plants from Zimbabwe against Mycobacterium aurum and Corynebacterium glutamicum. Trop Biomed. 2010;27:595-610.

36. Chukwudi U, Ayodeji F, Amos J, Olawunmi O. Antibacterial activity and phytochemical evaluation of the leaf root and stem bark extracts of Parinari curatellifolia (planch. Ex benth). Int. J Adv Chem. 2014;2:178-81.

37. Maroyi A. Traditional use of medicinal plants in south-central Zimbabwe: review and perspectives. J Ethnobiol Ethnomed. 2013;9:31.

38. Barchan A, Bakkali M, Arakrak A, Pagán R, Laglaoui A. The effects of solvents polarity on the phenolic contents and antioxidant activity of three Mentha species extracts. Int J Curr Microbiol App Sci. 2014;3:399-412.

39. Lekganyane MA, Matsebatlela TM, Howard RL, Shai LJ, Masoko P. The phytochemical, antibacterial and antioxidant activity of five medicinal plants against the wound infecting bacteria. Afr J Biotechnol. 2012;11:13210-9.

40. Zumla A, Nahid P, Cole ST. Classification of drugs used to treat drugsusceptible and drug-resistant tuberculosis from advances in the development of new tuberculosis drugs and treatment regimens. Nat Rev Drug Discov. 2013;12:388-404. doi:10.1038/nrd4001.

41. Taniguchi H, Chang B, Abe C, Nikaido Y, Mizuguchi Y, Yoshida SI. Molecular analysis of kanamycin and viomycin resistance in Mycobacterium smegmatis by use of the conjugation system. J Bacteriol. 1997;179:4795-801.

42. Danilchanka O, Pavlenock M, Niederwis M. Role of porins for uptake of antibiotics by mycobacterium smegmatis. Antimicrob Agents Chemother. 2008:52:3127-34.

43. Sant'Anna da Silva AP, Nascimento da Silva LC, Martins da Fonseca CS, de Araújo JM, dos Santos Correia MT, da Silva Cavalcanti M, and Menezes Lima VL. Antimicrobial Activity and Phytochemical Analysis of Organic Extracts from Cleome spinosa Jaqc. Front Microbiol. 2016; 7: 963.

44. Sasidharan S, Chen Y, Saravanan D, Sundram KM, Yoga LL. Extraction, isolation and characterization of bioactive compounds from Plants' extracts. Afr J Tradit Complement Altern Med. 2011;8(1):1-10.

45. Tsao R, Romanchuk FE, Peterson CJ, Coats JR. Plant growth regulatory effect and insecticidal activity of the extracts of the tree of heaven (Ailanthus altissima L.). BMC Ecol. 2002;2:1.

46. Upadhyay A, Upadhyaya I, Kollanoor-Johny A, Venkitanarayanan K. Combating pathogenic microorganisms using plant-derived antimicrobials: a Minireview of the mechanistic basis. Biomed Res Int. 2014;2014:761741.

47. Cowan MM. Plant products as antimicrobial agents. Clin Microbiol Rev. 1999;12:564-82.

48. Samy RP, Gopalakrishnakone P. Therapeutic potential of plants as anti-microbials for drug discovery. Evid Based Complement Alternat Med. 2010;7:283-94.

49. Rabin N. Zheng1 Y, Opoku-Temeng C, du Y, Bonsu E, Sintim HO. Agents that inhibit bacterial biofilm formation. Future med. Chem. 2015;7:647-71.

50. Vassea M, Robert J. Noble RJ, Akhmetzhanov AR, Gurney CT-BJ, Benateau S, Gougat-Barbera C, Kaltz O, Hochberg ME. Antibiotic stress selects against cooperation in the pathogenic bacterium Pseudomonas aeruginosa. 546-551 PNAS. 2017; 114: 546-551. 